\title{
${ }^{99 \mathrm{~m}}$ Tc-labelled biguanide derivatives: chemical speciation modelling thereof and evaluation in vervets
}

\author{
Jan Rijn Zeevaart ${ }^{1}$, Judith Marie Wagener ${ }^{1}$, Maria Neves ${ }^{2}$, Maria Ceu Costa ${ }^{3}$, \\ Cristina Rodrigues $^{3}$, Mildred Dithebe ${ }^{4}$, Elmaré Kilian ${ }^{5}$ and Ignacy Cukrowski ${ }^{6}$
}

(1) Department of Radiochemistry, NECSA, PO Box 582, Pretoria, 0001, South Africa

(2) Instituto Tecnologico Nuclear, 2686-953 Sacavem, Portugal

(3) Instituto Nacional de Engenharia, Tecnologia e Inovação, I.P., 1649-038 Lisbon, Portugal

(4) CARST, North West University, Mafikeng Campus, Mmabatho, 2735, South Africa

(5) UPBRC, Onderstepoort, University of Pretoria, Pretoria, 0002, South Africa

(6) Department of Chemistry, University of Pretoria, Pretoria, 0002, South Africa

Email: zeevaart@necsa.co.za

Abstract ${ }^{99 \mathrm{~m}}$ Tc-DMSA (dimercaptosuccinic acid) is known to be a safe and effective agent for static renal imaging. However, it has a long uptake time which is a limiting factor in diagnostic procedures and also leads to a relatively high radiation dose being administered to patients. There is a constant search for possible new renal imaging agents with a good resolution, kidney/liver contrast and low radiation dose to all organs. A series of biguanide derivatives (potential as noninsulin-dependent diabetes mellitus agents) labelled with ${ }^{99 \mathrm{~m}} \mathrm{Tc}$ were investigated as potential alternative kidney-imaging agents on theoretical grounds (in silico) and their biodistribution (in vivo) verified in a limited number of animal experiments. Such a dual approach has the benefit that it reduces the number of animal experiments needed to evaluate a potential radiopharmaceutical. The blood plasma model shows little or no complexation of the biguanide type ligands by the metal ions in blood plasma. It was therefore expected that these ligands will clear rapidly through the kidneys and liver (increased lipophilicity). These predictions were verified by studies on single vervets comparing them with ${ }^{99 m}$ Tc-DMSA as gold standard. All the biguanide derivatives labelled with ${ }^{99 \mathrm{~m}}$ Tc show liver, kidney and gallbladder uptake in vervets. It was shown that the agent ${ }^{99 m} \mathrm{Tc}-$ CBIG (carboxylbiguanide) has a very fast kidney clearance, which will reduce the dose to organs (as experienced for ${ }^{99 \mathrm{~m}}$ Tc-DMSA), although it's potential as a kidney agent is limited by its gallbladder uptake.

Keywords Biguanides - Blood plasma speciation - Kidney agents

\section{Introduction}

In the field of diagnostic radiopharmaceuticals, a number of successful ${ }^{99 m}$ Tc-based radiopharmaceuticals are available in the market because of the availability of ${ }^{99 \mathrm{~m}} \mathrm{Tc}$ from generators on demand. Furthermore, its half-life $(6 \mathrm{~h})$ and $140 \mathrm{keV}$ gamma make it the almost ideal isotope for imaging of biological processes. Many ${ }^{99 m} \mathrm{Tc}$-based radiopharmaceuticals were designed in the 1980s and 1990s, one area being kidney diagnostic agents.

Renal imaging agents are used to evaluate the anatomy and function of the kidneys. Its excretory function is most easily assessed by radioscintigraphy. Small ionic scintigraphic agents are eliminated from the blood by the kidneys and are readily monitored by sequential camera images. Computer-assisted processing of the dynamic renal function images provides direct information on the renal blood/plasma flow (via the agent ${ }^{99 \mathrm{~m}} \mathrm{Tc}_{\mathrm{M}} \mathrm{MAG}_{3}$ ), the glomerular filtration rate $\left({ }^{99 \mathrm{~m}} \mathrm{Tc}\right.$-DTPA) and assessment of the functional renal mass ( $\left.{ }^{99 m} \mathrm{Tc}-\mathrm{DMSA}\right)$. Quantification of these parameters yields an invaluable diagnostic aid, which is particularly useful in evaluating kidney transplants [1]. 
${ }^{99 m}$ Tc-DMSA is used for imaging the morphology of the renal cortex. After intravenous injection, the agent is substantially bound to plasma protein and is thus not filtered by the glomerulus. After entering the kidney, the agent localises in the cortex [2].

Although ${ }^{99 m}$ Tc-DMSA is known to be a safe and effective agent for static renal imaging, the renal uptake of 3-6 h p.i. of ${ }^{99 \mathrm{~m}}$ Tc-DMSA is a limiting factor in diagnostic procedures, as it implies that a patient is injected 3-6 h prior to scanning (with the associated discomfort) and subsequently discharged. It also leads to a relatively high radiation dose, as ${ }^{99 \mathrm{~m}} \mathrm{Tc}$ has a short half-life of $6 \mathrm{~h}$, which means that the patient is injected with twice the amount of activity than if the scan were to be carried out immediately.

Because of these drawbacks, there is a search for possible new renal imaging agents with a good resolution, kidney/liver contrast and low radiation dose to all organs. Thus attempts are made to improve the adverse aspects of DMSA, for instance ${ }^{99 \mathrm{~m}} \mathrm{Tc}$-Biguanide (BIG). It was shown [3, 4$]$ that ${ }^{99 \mathrm{~m}} \mathrm{Tc}-\mathrm{BIG}$ had a high kidney uptake after $30 \mathrm{~min}$, lower kidney uptake after $4 \mathrm{~h}$, a good kidney to liver ratio $(2.5: 1)$ which resulted in an overall lower dose to organs while static renal imaging was still possible.

In the past, the search for new radiopharmaceuticals was based on a trial-and-error approach leading to a large number of animal studies needed to evaluate a new potential radiopharmaceutical. Our group has recorded some success in using a blood plasma model in predicting and describing potential bone-seeking agents (bisphosphonates) [ $\underline{5}-7]$ as opposed to a trial-and-error approach. Most of the agents screened by this in vitro/in silico technique were not found to have potential and drawbacks were indicated. These were then proven by selected animal tests. Such a dual approach has the benefit that it reduces the number of animal experiments needed to evaluate a potential radiopharmaceutical. The models could also elucidate the in vivo behaviour found. Although the model has thus far not predicted improved bone-seeking radiopharmaceuticals, its success lies in the faster screening of agents and in avoiding excessive animal testing. For the work described in this publication, an attempt was made to use the same approach, although the formation constants for Tc could not be measured. As it has been demonstrated $[3,4]$ that ${ }^{99 \mathrm{~m}}$ Tc-BIG has potential as kidney agent other Biguanide derivatives were investigated in this work.

In order to establish a blood plasma model for Tc one needs to measure or estimate the formation constants for Tc with all the blood plasma ligands. This is not really feasible. There is no stable isotope of Tc, although ${ }^{999}$ Tc has a half-life of 211,000 years and could be used it is an isotope with a high contamination risk due to its long half-life makes. Therefore, it is not surprising that only a few formation constants are available in the NIST database [8]. Although one can use the linear free energy relationship (LFER) plots to estimate formation constants of an unknown metal ion [6], one needs a few reliable formation constants to compare with other metal ions. Not one of the formation constants for Tc (including for hydroxide) meets the criteria for the NIST database [8]. This implied that the LFER technique was not an option.

However, if one considers that ${ }^{99 m} \mathrm{Tc}$ is no-carrier-included [9], it implies that the amount of Tc is between 0.2 and $1 \mathrm{nmol}$ per injected dose, while the corresponding amount of ligand is $5.5 \mu \mathrm{mol}$ (if $1 \mathrm{mg}$ of DMSA is taken) [10]. It means that the number of Tc metal ions injected is minimal (one Tc atom per 5,500 to 27,500 DMSA molecules), which leads us to believe that one could approach the blood plasma modelling without the Tc-ligand formation constants. One would simply measure the constants of the ligand with the main blood plasma metal ions as well as the $\mathrm{Sn}$ (II) (which is normally included in the formulations as a reducing agent [10]) and see whether there is any significant binding of blood plasma metal ions. If this is not the case, one can assume that the Tccomplex stays intact when introduced into the blood plasma [11]. This approach is further reinforced if one considers that all the biguanide derivatives (see Fig. 1) have nitrogen donor atoms, which means that ${ }^{99 \mathrm{~m}} \mathrm{Tc}$ will form strong complexes with these ligands [12] which should remain intact in blood plasma. $\mathrm{ML}_{2}$ complexes are formed with $\mathrm{Tc}(\mathrm{V})$ and $\operatorname{Re}(\mathrm{V})$ via a bidentate 
binding by two nitrogen donor atoms [12]. The amount of $\mathrm{Sn}(\mathrm{II})$ added to the formulation $(0.42 \mathrm{mg}$ $\mathrm{SnCl}_{2} \cdot 2 \mathrm{H}_{2} \mathrm{O}$ ) is $2 \mu \mathrm{mol}$, which is $2,000-10,000$ times that of $\mathrm{Tc}$, which implies that $>99.9 \%$ of the $\mathrm{Sn}(\mathrm{II})$ is available for complexation and will not be oxidised to Sn(IV) in the process of converting $\mathrm{Tc}$ to the pertechnetate form. The other compounds concerned, ascorbic acid $0.7 \mathrm{mg}$ and $\mathrm{NaCl}$ $2.9 \mathrm{mg}$, will not influence the blood plasma, as they already are blood plasma constituents at higher concentrations [11].<smiles>N=C(N)NC(=N)N</smiles>

(a) Biguanide, $\mathrm{BIG},\left(\mathrm{C}_{2} \mathrm{H}_{7} \mathrm{~N}_{5}\right)$<smiles>NC(=O)NC(N)=O</smiles><smiles>CN(C)C(=N)NC(=N)N</smiles>

(b) Dimethytbiguanide, DMBG, $\left(\mathrm{C}_{4} \mathrm{H}_{11} \mathrm{~N}_{5}\right)$<smiles>NC(=O)NC(N)=O</smiles>

(c) cis and trans Biuret, BIU, $\left(\mathrm{C}_{2} \mathrm{H}_{5} \mathrm{~N}_{3} \mathrm{O}_{2}\right)$<smiles>N=C(N)NC(N)=S</smiles>

(d) 2-Imino-4-Thiobiuret, ITB, $\left(\mathrm{C}_{2} \mathrm{H}_{6} \mathrm{~N}_{4} \mathrm{~S}\right)$<smiles>N=C(N)NC(=N)NCCC(=O)O</smiles>

(e) carboxy-biguanide (CBIG)

Fig. 1 Ligands discussed in this paper: a Biguanide, BIG $\left(\mathrm{C}_{2} \mathrm{H}_{7} \mathrm{~N}_{5}\right)$, $\boldsymbol{b}$ dimethyl biguanide, DMBG $\left(\mathrm{C}_{4} \mathrm{H}_{11} \mathrm{~N}_{5}\right)$, $\boldsymbol{c}$ cis and trans Biuret, BIU $\left(\mathrm{C}_{2} \mathrm{H}_{5} \mathrm{~N}_{3} \mathrm{O}_{2}\right)$, d 2-imino-4-thiobiuret, ITB $\left(\mathrm{C}_{2} \mathrm{H}_{6} \mathrm{~N}_{4} \mathrm{~S}\right)$, and e carboxy-biguanide (CBIG)

A number of biguanide-related molecules were tested and compared against/with DMSA in the animal experiments reported in this paper. Dimethyl biguanide (DMBG), -biuret (BIU), -2-imino-4thiobiuret (ITB) and -carboxy-biguanide (CBIG), collectively referred to as L, are shown in Fig. 1. CBIG is a molecule that was designed to improve on the success achieved with biguanide (BIG) [3]. It is essentially an addition of a carboxyl group on the amine of BIG and might help in the coordination to the Tc metal ion and should reduce the number of tautomers that can be written for BIG. It will also lower the charge of the complex. As base is used during the labelling process, one can assume that $\mathrm{BIG}$ is not in the Zwitter ionic form and will form $\left[\mathrm{TcO}(\mathrm{BIG})_{2}\right]^{+}$complexes as indicated previously [12]. For $\mathrm{CBIG}$, the complex is postulated to be [TcO(BIG-COO $\left.)_{2}\right]^{-}$which could assist in its clearance from the kidneys. There is also a possibility that the COO group will complex to the Tc $=\mathrm{O}$ centre, although this is not expected. Finally, biguanides are anti-diabetic agents [13] and therefore liver uptake is expected as well as kidney uptake (demonstrated for $\left.{ }^{99 \mathrm{~m}} \mathrm{Tc}-\mathrm{BIG}\right)$.

\section{Materials and methods}

\section{General}

The ligands dimethyl biguanide (DMBG) (Sigma, St. Loius), 2-imino-4-thiobiuret (ITB) (SigmaFluka) and biuret (BIU) (Sigma-Aldrich) are commercially available. 
Synthesis of Carboxyl-biguanide (CBIG) was performed according to the method of Vaillancourt, et al [14] using biguaniminoethanoic acid as starting material, as follows.

\section{Carbamimidothioic acid}

Guanylthiourea (12.5 g, $106 \mathrm{mmol})$ was added to dry ethanol (85 $\mathrm{mL})$ at room temperature and elevated to $60{ }^{\circ} \mathrm{C}$. Iodomethane $(10 \mathrm{~mL}, 160 \mathrm{mmol})$ was slowly added and the mixture was stirred for $2 \mathrm{~h}$. Then the solvent was removed in a rotary evaporator at $30-35^{\circ} \mathrm{C}$ to give a solid which was washed with cold ethanol to give carbimidothioic acid as white crystals $(27.1 \mathrm{~g}, 98.5 \%)$, melting point (m.p.) $124{ }^{\circ} \mathrm{C} \mathrm{IV} \mathrm{(KBr):} U_{\max } 3341,3283(\mathrm{NH}$, str), 1627 (C=N str), 1580, 1520 and 1510 (NH bend), 1426 ( $\mathrm{SCH}_{3}$ bend) and 656 (CS str) $\mathrm{cm}^{-1}$. ${ }^{1} \mathrm{H}-\mathrm{NMR}: \delta_{\mathrm{H}}\left(3000 \mathrm{MHz} ; \mathrm{D}_{2} \mathrm{O}\right) 2.25$ (3H, s, 3-Me) ppm.; ${ }^{13} \mathrm{C}-\mathrm{NMR}: \delta_{\mathrm{c}}\left(300 \mathrm{MHz}\right.$; D $\mathrm{O}_{2}$, DMSO) 181.06 (C-3) ppm; ESI-ITD MS: 132 $\left(100 \%,[\mathrm{M}+\mathrm{H}]^{+}\right), 90\left(8 \%,\left[\mathrm{M}-\mathrm{H}_{2} \mathrm{NCNH}\right]^{+}\right), 60\left(29 \%,[\mathrm{M}-\mathrm{NHCNHS}]^{+}\right) \mathrm{m} / \mathrm{z} ; \mathrm{MS} / \mathrm{MS}(132): 90(100 \%$, $\left.\left[\mathrm{M}-\mathrm{H}_{2} \mathrm{NCNH}\right]^{+}\right), 85\left(17 \%,\left[\mathrm{M}-\mathrm{SCH}_{3}\right]^{+}\right), 60\left(29 \%,[\mathrm{M}-\mathrm{NHCNHS}]^{+}\right) \mathrm{m} / \mathrm{z}$.

\section{Biguaniminopropanoic acid (CBIG)}

B-Alanine $(3.01 \mathrm{~g}, 33.8 \mathrm{mmol})$ was suspended in absolute ethanol $(100 \mathrm{~mL})$, and heated at $60{ }^{\circ} \mathrm{C}$. Then, triethylamine $(10 \mathrm{~mL})$ was slowly added, followed by water $(10 \mathrm{~mL})$ and the mixture was stirred until dissolution of the aminoacid was achieved $(\sim 2 \mathrm{~h})$. Carbamimidothioic acid (Eilingsfield and Scheuermann 1967; 15] was added $(10.23 \mathrm{~g}, 39.3 \mathrm{mmol})$ in 6 portions over $\sim 6 \mathrm{~h}$ and the mixture stirred at $60^{\circ} \mathrm{C}$ for $20 \mathrm{~h}$. The mixture was cooled to room temperature and the precipitated solid was filtered, washed with ethanol and dried to give a white powder (2.7 g, 46.3\%), m.p. 240$242{ }^{\circ} \mathrm{C}$; IV (KBr): $U_{\max } 3413,3287(\mathrm{NH}, \mathrm{str}), 3226,1648,737 \mathrm{~cm}^{-1}$. ${ }^{1} \mathrm{H}-\mathrm{NMR}: \delta_{\mathrm{H}}\left(300 \mathrm{MHz} ; \mathrm{D}_{2} \mathrm{O}\right)$ $3.23(2 \mathrm{H}, \mathrm{t}, \mathrm{J}=6.6 \mathrm{~Hz}, 4-\mathrm{H}), 2.25(2 \mathrm{H}, \mathrm{t}, \mathrm{J}=6.6 \mathrm{~Hz}, 3-\mathrm{H}) \mathrm{ppm} ;{ }^{13} \mathrm{C}-\mathrm{NMR}: \delta_{\mathrm{C}}\left(300 \mathrm{MHz} ; \mathrm{D}_{2} \mathrm{O}\right.$, DMSO) 176.11 (C-5), 155.84 (C-1 and C-2), 34.89 (C-3), 32.50 (C-4) ppm; ESI-ITD MS: 174 $\left(100 \%,[\mathrm{M}+\mathrm{H}]^{+}\right), 159\left(14 \%,[\mathrm{M}-\mathrm{NH}]^{+}\right), 133\left(11 \%,[\mathrm{M}-\mathrm{HNCN}]^{+}\right) \mathrm{m} / \mathrm{z} ; \mathrm{MS} / \mathrm{MS}(174): 157(22 \%,[\mathrm{M}-$ $\left.\mathrm{OH}]^{+}\right), 151\left(99 \%,\left[\mathrm{M}-\mathrm{HNCN}+\mathrm{H}_{2} \mathrm{O}\right]^{+}\right), 133\left(56 \%,[\mathrm{M}-\mathrm{HNCN}]^{+}\right), 132\left(36 \%[\mathrm{M}-\mathrm{NCN}]^{+}\right) \mathrm{m} / \mathrm{z}$.

All reagents were of analytically pure grade, while all solutions used in preparing ${ }^{99 \mathrm{~m}} \mathrm{Tc}-\mathrm{L}$ were deoxygenized by purging with argon.

\section{Blood plasma modelling}

The evaluation of constituent concentrations for large equilibrium studies (ECCLES) program [16] was used for speciation calculations in this paper. This is a well described suite of programs [16] and its use to predict the in vivo behaviour illustrated in several earlier papers [ $\underline{5}-\underline{7}]$ and therefore no detail of this approach is given here. Briefly, the ECCLES formation constant database was updated to include formation constants for the biguanide-type ligands and DMSA with the blood plasma metal ions $\mathrm{Ca}(\mathrm{II}), \mathrm{Mg}(\mathrm{II}), \mathrm{Zn}(\mathrm{II})$ that were established previously and published elsewhere [11]. The concentrations used to model the metal ion complex in blood plasma were based on the expected amounts of the individual compounds that would be present in blood after injection of a standard amount of these complexes. The amount of blood in a monkey was estimated to be $60 \mathrm{~mL}$ per $\mathrm{kg}$ body weight and the average weight of the vervet monkeys was $6 \mathrm{~kg}$. A blood volume of $360 \mathrm{~mL}$ was assumed and the concentration of ligand in blood plasma was calculated to be $5.0 \times 10^{-5} \mathrm{~mol} \mathrm{dm}^{-3}$ for DMBG, $7.3 \times 10^{-5} \mathrm{~mol} \mathrm{dm}^{-3}$ for BIU, $6.3 \times 10^{-5} \mathrm{~mol} \mathrm{dm}^{-3}$ for ITB, $4.3 \times 10^{-5} \mathrm{~mol} \mathrm{dm}^{-3}$ for CBIG, and $1.4 \times 10^{-5} \mathrm{~mol} \mathrm{dm}^{-3}$ for DMSA. For the modelling of the Sn(II)DMBG complex a concentration of $1.9 \times 10^{-4} \mathrm{~mol} \mathrm{dm}^{-3}$ for $\mathrm{Sn}$ (II) was used in addition to the DMBG. The corresponding free $\mathrm{Sn}(\mathrm{II})$ concentration was $1.6 \times 10^{-5} \mathrm{~mol} \mathrm{dm}^{-3}$. Part of the output of the ECCLES program is the plasma-mobilising index (p.m.i). These values are defined as:

\section{p.m.i $=\frac{\text { Total l.m.m metal icn concentration in the precence of the agent }}{\text { Total l.m.m concentration in normal placma }}$}

where I.m.m = low-molecular-mass. The p.m.i values give an indication of which blood plasma metal ions are mobilized by the added ligand (which will act as a drug). 
For reasons stated earlier no formation constants for Tc were included in the blood plasma model and the assumption was made that the complex with Tc is strong and hence one only needs to consider the interaction of the ligand with the blood plasma metal ions.

\section{Preparation of ${ }^{99 \mathrm{~m}} \mathrm{TC}-\mathrm{L}$ and ${ }^{99 \mathrm{~m}} \mathrm{TC}-\mathrm{DMSA}$ and the determination of its radiochemical purity}

$0.5 \mathrm{~mL}$ of water were added to $3.00 \mathrm{mg}$ of $\mathrm{L}$ in an argon-filled sealed vial. After dissolution, $0.3 \mathrm{~mL}$ of $0.1 \mathrm{M} \mathrm{NaOH}$ were added, followed by $0.2 \mathrm{~mL}$ of a $\mathrm{SnCl}_{2} \cdot 2 \mathrm{H}_{2} \mathrm{O}(1.00 \mathrm{mg} / \mathrm{mL}$ in $0.001 \mathrm{M} \mathrm{HCl})$ solution. Immediately $0.5 \mathrm{~mL}^{99 \mathrm{~m}} \mathrm{TcO}_{4}{ }^{-}$(pertechnetate; freshly eluted from a ${ }^{99} \mathrm{Mo} /{ }^{99 \mathrm{~m}} \mathrm{Tc}$ Peltek Generator, NTP Radioisotopes Pty. Ltd., Pretoria, South Africa) were injected into the vial. The reaction mixture was incubated at room temperature for $15 \mathrm{~min}$.

The radiochemical purity of the ${ }^{99 \mathrm{~m}} \mathrm{Tc}$-L complex was assessed by HPLC system consisting of Agilent Zorbax $\mathrm{NH}_{2}$ column ( $5 \mu \mathrm{m}$ pore size, $4.6 \mathrm{~mm}$ ID $\times 250 \mathrm{~mm}$ ), the Variant ProStar model 230 dual pumps, the synchronized Rheodine 7725i injector, an in-line Variant ProStar model 325 UV and VIS detector and a single sodium iodide crystal flow radioactivity detector (Raytest Gabi.) All HPLC chromatograms were recorded by a Variant Star 800 channel control/interface module connected to a computer running Galaxie Chromatographic Data System software. The radioactive chromatograms obtained using the Gina Star 4.07 version of software. Elution was carried out by water/acetonitrile gradient elution starting with 5/95 mixture after 17 min was changed to 100/0 mixture up to $27 \mathrm{~min}$ and kept constant for $10 \mathrm{~min}$, whereafter it was increased back to 5/95 mixture for $8 \mathrm{~min}$ and kept at this level for $5 \mathrm{~min}$ till the end of the chromatographic elution.

${ }^{99 m}$ Tc-DMSA was prepared from the Amerscan ${ }^{\mathrm{TM}}$ DMSA agent N107 [10] kit by following the instructions in the leaflet and ${ }^{99 \mathrm{~m}} \mathrm{TcO}_{4}{ }^{-}$(pertechnetate) as described above. A radiochemical purity of $95 \%$ was recorded.

\section{Biodistribution and pharmacokinetics of ${ }^{99 \mathrm{~m}} \mathrm{Tc}-\mathrm{L}$ and ${ }^{99 \mathrm{~m}} \mathrm{TC}-\mathrm{DMSA}$}

According to the policies and procedures of the University of Pretoria, baboons are currently not used for research, but vervet monkeys (Cercopethicus aethiops) are. In order to compare the information gathered from the previous study [4] with the information to be obtained from the planned study, a similar animal model had to be used. It is known that the biodistribution of different radiopharmaceuticals in baboons is comparable to the biodistribution in monkeys. As kidney imaging is evaluated, the larger kidney in monkeys is preferable to that of rodents, since it will give a clearer kidney image and help with the evaluation of the kidney's morphology. Only nonterminal single animal experiments (one animal per radiopharmaceutical) were approved by the Ethics Committee of the University of Pretoria, according to the guidelines of the National Code for Animal Use in Research, Education, Diagnosis and Testing of Drugs and Related Substances in South Africa. As these experiments were to prove the deductions made from the blood plasma modelling, it was viewed sufficient to have only single animal experiments per ligand studied.

Five adult male vervet monkeys (average weight $6.0 \mathrm{~kg}$ ) were obtained from the UBPRC at Onderstepoort (South Africa) and subjected to identical experimental procedures. The animals were kept in separate cages and provided with husbandry and management practices with the emphasis on environmental enrichment to optimize the health and mental status of the animals. The animals were fed a balanced diet and water ad libitum. The animals were made to fast for 12$16 \mathrm{~h}$ prior to the experiment and immobilized with $10 \mathrm{mg} / \mathrm{kg}$ of ketamine hydrochloride $100 \mathrm{mg} / \mathrm{mL}$ (The Premier Pharmaceutical Company Ltd., S.A.) and $0.5 \mathrm{mg} / \mathrm{kg}$ of midazolam $5 \mathrm{mg} / \mathrm{mL}$ (Roche Products Pty Ltd., S.A.). Blood samples were collected from the catheter in the femoral artery. The animals were then catheterised for urine collection and $\sim 5 \mathrm{mCi}$ of tracer was intravenously injected while the animals were positioned in the supine position under the Siemens Orbitor Gamma 
camera. A $1 \mathrm{~h}$ dynamic study was performed, followed by 2 min static studies on the hour up to $4 \mathrm{~h}$. Blood $(2 \mathrm{~mL})$ and urine $(1 \mathrm{~mL})$ were collected at various time intervals to determine the blood circulation time and excretion of the different radiopharmaceuticals.

Regions of interest (ROIs) were placed on the images of cardiac blood pool, liver, lung, gallbladder, kidneys, and bone (cortical and trabecular) to obtain time-activity curves from the dynamic study. Similarly, data of count-rate per pixel for the ROls, which were decay-corrected, were obtained from the static images. These were normalised to extend the time-activity curves of the dynamic study to $4 \mathrm{~h}$.

Blood clearance and cumulative urine curves were also obtained in all cases so that relative organ distributions of the retained activity and eventually of the injected dose (i.d.) could be obtained for all ${ }^{99 \mathrm{~m}}$ Tc-labelled complexes.

\section{Results}

Table 1 shows the species distribution in blood plasma for each ligand. Table 2 shows the species distribution of $\mathrm{Sn}(\mathrm{II})$ in combination with DMBG. Figure 2 shows the p.m.i. curves for $\mathrm{Mg}(\mathrm{II})-\mathrm{ITB}$, $\mathrm{Zn}(\mathrm{II})-\mathrm{CBIG}$ and $\mathrm{Zn}(\mathrm{II})$-DMSA. Only these curves are shown, as all other combinations of the studied ligands with the blood plasma metal ions gave curves with no inclination/elevation up to log [Ligand] $=-2$. The HPLC QC showed that the radiochemical purity of the final product was higher than $95 \%$. The radiochromatogram for ${ }^{99 \mathrm{~m}} \mathrm{Tc}-\mathrm{BIU}$ is shown in Fig. $\underline{3}$. Scintigraphic images of individual representative animals after injection of ${ }^{99 \mathrm{~m}} \mathrm{Tc}-\mathrm{DMBG},{ }^{99 \mathrm{~m}} \mathrm{Tc}-\mathrm{BIU},{ }^{99 \mathrm{~m}} \mathrm{Tc}$-ITB, ${ }^{99 \mathrm{~m}} \mathrm{Tc}-\mathrm{CBIG}$ and ${ }^{99 \mathrm{~m}} \mathrm{Tc}$-DMSA are shown in Fig. 4. The thorax images at 1, 2, 2.5 and $3 \mathrm{~h}$ after injection are presented. Table $\underline{3}$ contains the mean $t_{1 / 2}$, the halftime of clearance, and values for all the tracers in various organs. Table 4 contains the $\%$ of injected dose (\% i.d.) values of various organs at 1,2 , 2.5 and $3 \mathrm{~h}$ as well as the \% of the compound excreted through the urine. Figure $\underline{5}$ presents the individual blood clearance curve for all tracers, while Fig. $\underline{6}$ shows the individual urine clearance curves.

Table $1 \%$ Species distribution of all ligands studied at the blood concentration used in the animal experiments

\begin{tabular}{|c|c|c|c|c|c|c|c|c|}
\hline & Free ligand (L) & LH & Mg-L & Zn-L & $\mathrm{Zn}_{2}-\mathrm{L}_{2}-(\mathrm{OH})$ & $\mathrm{Zn}_{2}-\mathrm{L}_{2}-(\mathrm{OH})_{2}$ & $\mathrm{Zn}_{2}-\mathrm{L}_{2}-(\mathrm{OH})_{3}$ & Sn-L-(OH) \\
\hline DMBG & 0 & 100 & & & & & & \\
\hline $\mathrm{DMBG}^{\mathrm{a}}$ & 0 & 75.5 & & & & & & 25.5 \\
\hline BIU & 0.1 & 99.9 & & & & & & \\
\hline ITB & 87.6 & 1.9 & 10.4 & & & & & \\
\hline CBIG & 98.3 & & 0.1 & 1.5 & & & & \\
\hline DMSA & & & & & 3.1 & 96.8 & 0.1 & \\
\hline
\end{tabular}

$\mathrm{Zn}$ refers to $\mathrm{Zn}(\mathrm{II})$ and $\mathrm{Mg}$ to $\mathrm{Mg}(\mathrm{II})$

${ }^{a} \mathrm{Sn}(\mathrm{II})$ included in modelling

Table $2 \%$ Species distribution of Sn(II) with DMBG included

\begin{tabular}{|l|l|l|l|l|l|l|l|}
\hline & $\operatorname{Sn}(\mathrm{OH})_{2}$ & $\begin{array}{l}\text { Sn-Histidine } \\
(\mathbf{O H})\end{array}$ & $\begin{array}{l}\text { Sn- } \\
\text { Cysteine }\end{array}$ & $\begin{array}{l}\mathrm{Sn}_{2} \\
(\text { Cysteine })_{2}\end{array}$ & $\begin{array}{l}\text { Sn- } \\
\text { Histidine }\end{array}$ & $\begin{array}{l}\text { Sn- } \\
\text { L(OH) }\end{array}$ & $\begin{array}{l}\mathrm{Sn}_{2^{-}} \\
\mathbf{L}(\mathbf{O H})_{2}\end{array}$ \\
\hline DMBG & 45.2 & 27.2 & 7.7 & 3.8 & 2.1 & 6.9 & \\
\hline
\end{tabular}




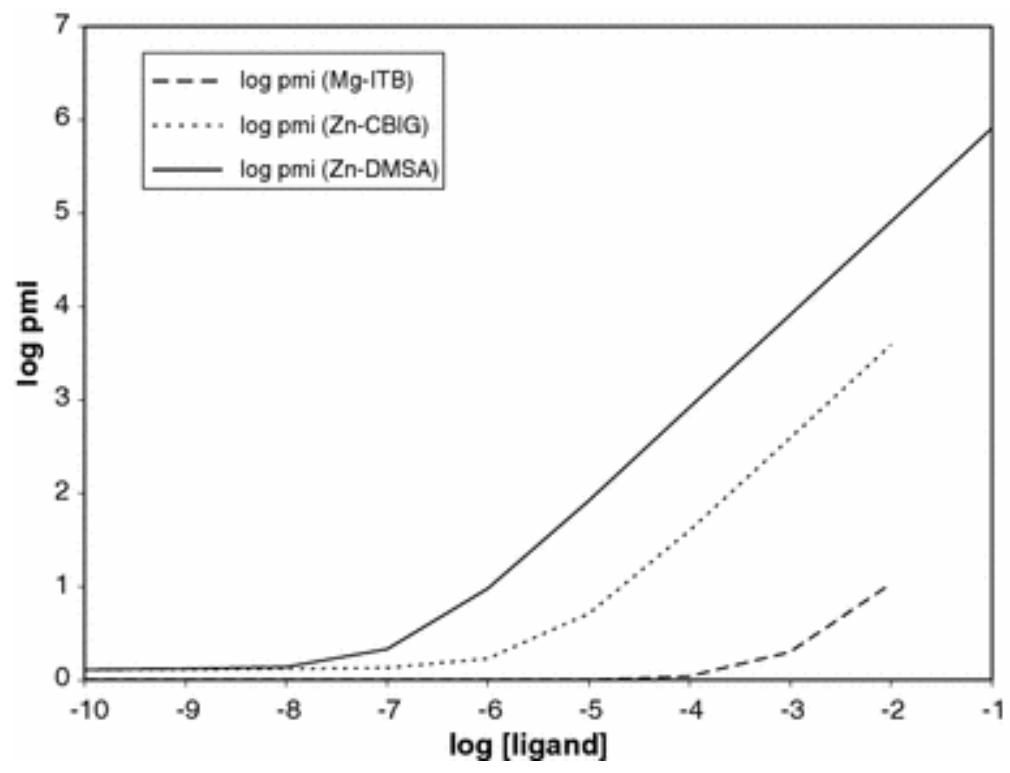

Fig. 2 Plasma mobilisation index (p.m.i.) curves for blood plasma metal ions versus ligand concentration with significant contribution. The arrows indicate the typical ligand concentrations used clinically
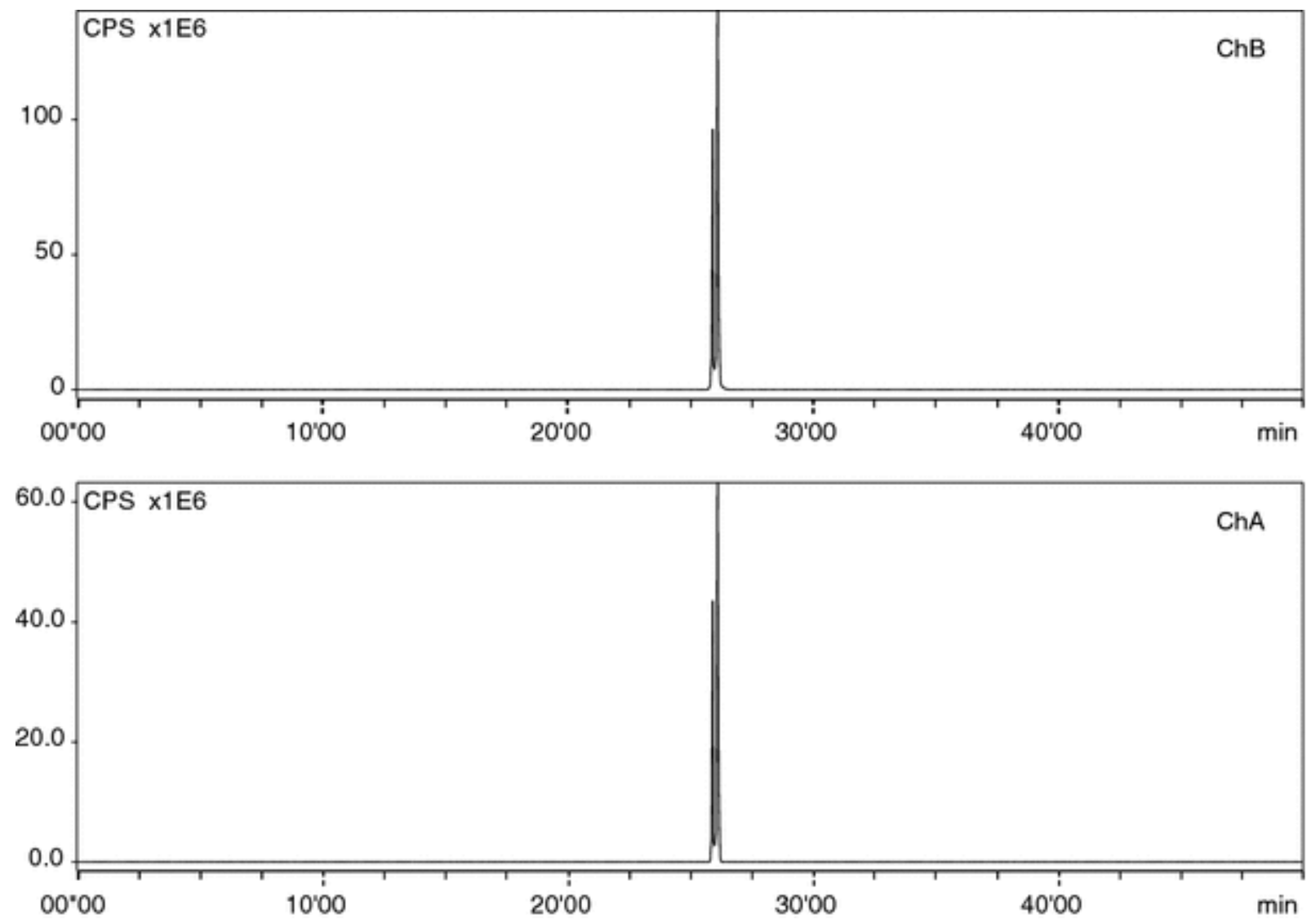

Fig. 3 Radiochromatogram of ${ }^{99 m} T C-B I U$ 


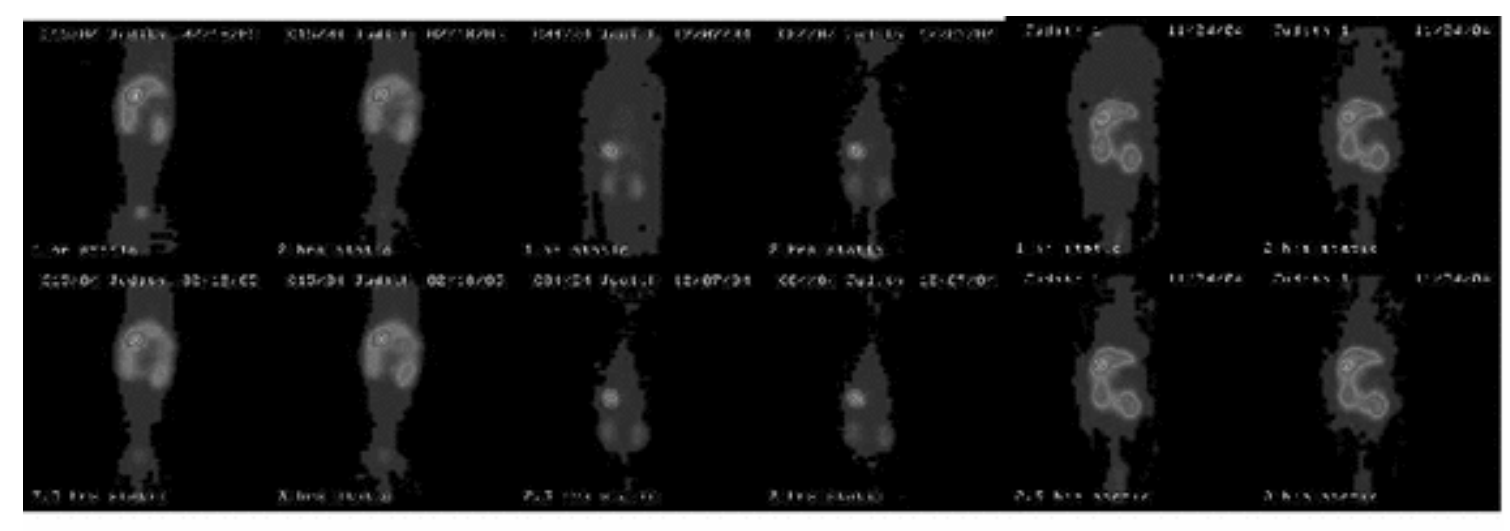

${ }^{99 \mathrm{~m}}$ Tc-DMBG $\quad{ }^{99 \mathrm{~m}}$ Tc-BIU

$99 \mathrm{~m}$ Tc-ITB

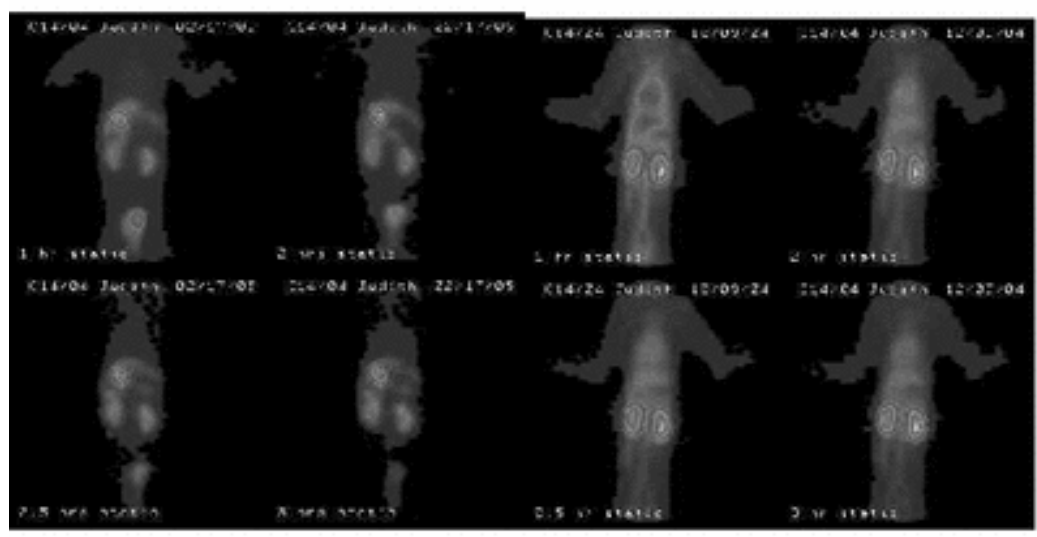

\section{${ }^{99 \mathrm{~m}}$ Tc-CBIG $\quad{ }^{99 \mathrm{~m}}$ Tc-DMSA}

Fig. 4 Scintigraphic thorax images at 1, 2, 2.5 and $3 \mathrm{~h}$ after injection of ${ }^{99 m} T C-D M B G,{ }^{99 m} T C-B I U,{ }^{99 m} T C-I T B,{ }^{99 m} T C-$ CBIG and ${ }^{99 m} T C-D M S A$ for individual representative animals

Table $3 T_{1 / 2}$ in minutes of ${ }^{99 m} T C-L$ and ${ }^{99 m} T C-D M S A$ in various body compartments of the animals and $t_{1 / 2}$ of blood clearance in $\min$

\begin{tabular}{|c|c|c|c|c|c|c|c|c|}
\hline Ligand & $\begin{array}{l}\text { Cardiac } \\
\text { blood pool } \\
\text { (min) }\end{array}$ & $\begin{array}{l}\text { Lung } \\
\text { (min) }\end{array}$ & $\begin{array}{l}\text { Liver } \\
\text { (min) }\end{array}$ & $\begin{array}{l}\text { Gallbladder } \\
\text { (min) }\end{array}$ & $\begin{array}{l}\text { Left } \\
\text { kidney } \\
\text { (min) }\end{array}$ & $\begin{array}{l}\text { Right } \\
\text { kidney } \\
\text { (min) }\end{array}$ & $\begin{array}{l}\text { Back- } \\
\text { ground } \\
\text { (min) }\end{array}$ & $\begin{array}{l}\text { Blood } \\
t_{1 / 2}(\min )\end{array}$ \\
\hline DMBG & 2 & 3 & $>180$ & $>180$ & $>180$ & $>180$ & 60 & 10 \\
\hline BIU & 3 & 5 & 12 & $>180$ & 4 & 5 & 15 & 2 \\
\hline ITB & 2 & 3 & $>180$ & $>180$ & $>180$ & $>180$ & 150 & 2 \\
\hline CBIG & 2 & 4 & 24 & 44 & 5 & 4 & 30 & 3 \\
\hline DMSA & 50 & 55 & $>180$ & $-{ }^{a}$ & $>180$ & $>180$ & $>180$ & 15 \\
\hline
\end{tabular}

${ }^{a}$ Not visible enough to be distinct from the liver 
Table 4 Percentage i.d. for various organs at various time intervals for the single animal experiments as well as \% urine excreted

\begin{tabular}{|c|c|c|c|c|c|c|c|c|}
\hline Ligand & $\begin{array}{l}\text { Time } \\
(\min )\end{array}$ & Liver & Gallbladder & $\begin{array}{l}\text { Left } \\
\text { kidney }\end{array}$ & $\begin{array}{l}\text { Right } \\
\text { kidney }\end{array}$ & $\begin{array}{l}\text { Urine } \\
\text { (\%) }\end{array}$ & Kidney/liver & Kidney/gallbladder \\
\hline \multirow{5}{*}{ DMBG } & 30 & 14.5 & 51.7 & 12.6 & 11.6 & 5.7 & 0.8 & 0.2 \\
\hline & 60 & 12.3 & 56.4 & 11.6 & 10.0 & 6.7 & 0.9 & 0.2 \\
\hline & 120 & 10.2 & 52.4 & 9.3 & 8.9 & 16.6 & 0.9 & 0.2 \\
\hline & 150 & 10.7 & 49.4 & 10.2 & 9.9 & 17.4 & 0.9 & 0.2 \\
\hline & 180 & 10.9 & 47.0 & 9.9 & 11.9 & 17.8 & 1.0 & 0.2 \\
\hline \multirow{5}{*}{ BIU } & 30 & 5.5 & 64.4 & 10.6 & 8.9 & 2.9 & 1.8 & \\
\hline & 60 & 3.2 & 71.8 & 6.9 & 6.0 & 7.9 & 2.0 & 0.2 \\
\hline & 120 & 1.7 & 70.7 & 4.6 & 4.8 & 15.8 & 2.8 & 0.1 \\
\hline & 150 & 1.5 & 71.1 & 4.5 & 4.8 & 16.0 & 3.1 & 0.1 \\
\hline & 180 & 1.5 & 70.8 & 4.3 & 4.4 & 16.7 & 2.9 & 0.1 \\
\hline \multirow{5}{*}{ ITB } & 30 & 19.4 & 40.8 & 15.1 & 18.5 & 3.8 & 0.9 & 0.4 \\
\hline & 60 & 15.7 & 43.3 & 12.6 & 16.0 & 10.7 & 0.9 & 0.3 \\
\hline & 120 & 10.8 & 31.7 & 9.5 & 10.5 & 36.6 & 0.9 & 0.3 \\
\hline & 150 & 9.4 & 29.7 & 10.4 & 11.1 & 38.4 & 1.1 & 0.4 \\
\hline & 180 & 8.6 & 28.9 & 9.6 & 9.8 & 42.4 & 1.1 & 0.3 \\
\hline \multirow{5}{*}{ CBIG } & 30 & 8.5 & 55.6 & 12.4 & 11.1 & 4.3 & 0.9 & 0.2 \\
\hline & 60 & 3.7 & 43.3 & 6.9 & 6.7 & 36.3 & 1.4 & 0.2 \\
\hline & 120 & 1.6 & 10.8 & 3.0 & 2.9 & 81.2 & 1.8 & 0.3 \\
\hline & 150 & 0.8 & 8.8 & 1.9 & 1.9 & 86.6 & 1.8 & 0.2 \\
\hline & 180 & 0.4 & 5.0 & 1.1 & 1.2 & 92.3 & 2.4 & 0.2 \\
\hline \multirow{5}{*}{ DMSA } & 30 & 12.4 & $-^{a}$ & 26.4 & 23.9 & 1.0 & 2.0 & \\
\hline & 60 & 10.0 & $-{ }^{a}$ & 32.5 & 28.7 & 2.1 & 3.1 & \\
\hline & 120 & 7.2 & $-^{a}$ & 36.3 & 30.1 & 7.3 & 4.6 & \\
\hline & 150 & 6.6 & $-{ }^{a}$ & 36.2 & 32.0 & 7.9 & 5.2 & \\
\hline & 180 & 6.2 & $-{ }^{a}$ & 3.3 & 32.9 & 8.3 & 5.7 & \\
\hline
\end{tabular}

${ }^{a}$ Not visible enough to be distinct from the liver 


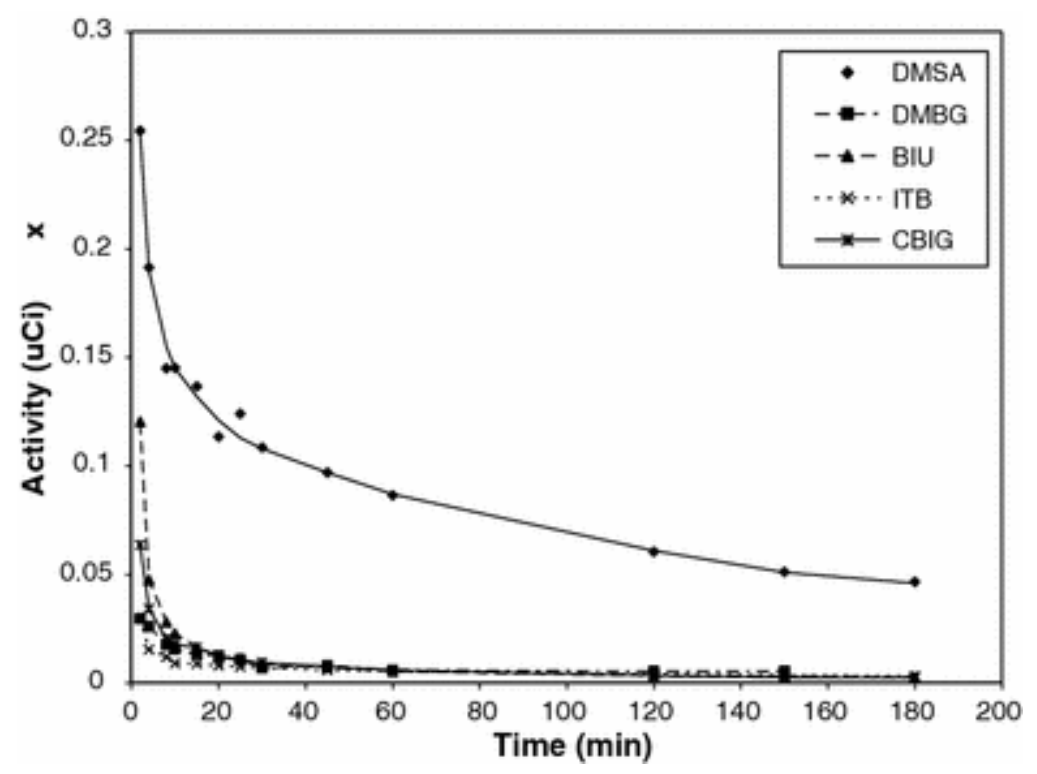

Fig. 5 Individual blood clearance curves, normalised to injected dose for all compounds

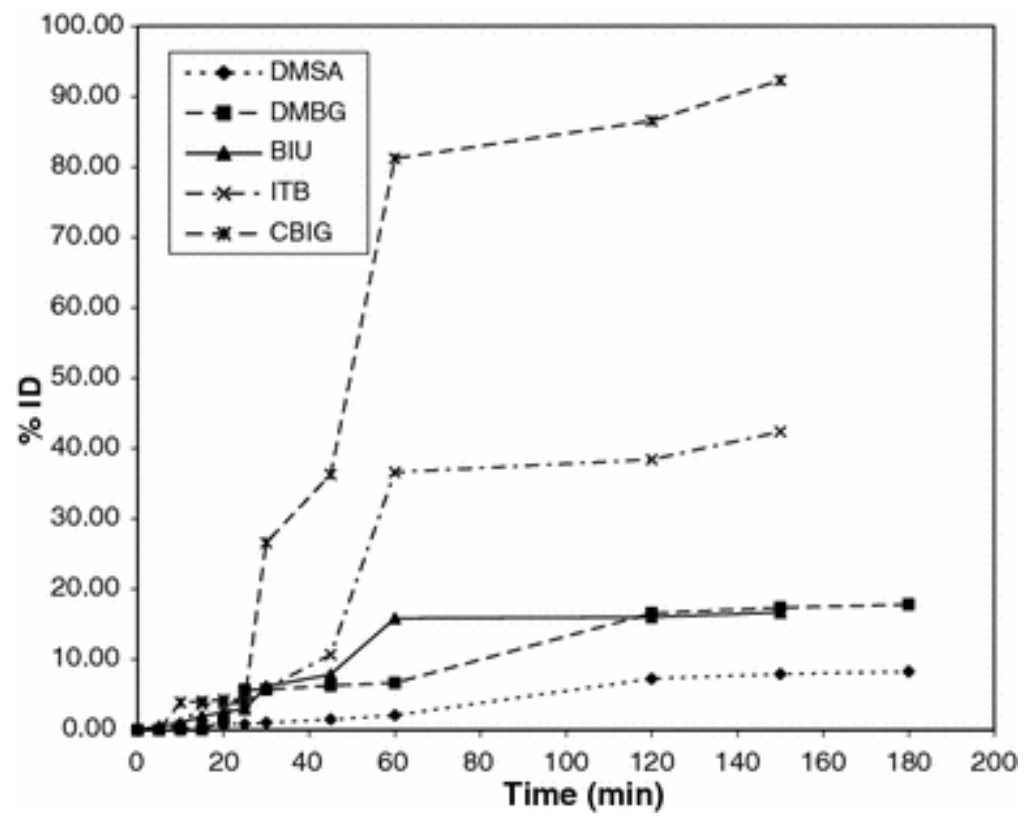

Fig. 6 Mean cumulative urinary excretion curve $(n=3)$ for all compounds as a percentage of i.d

\section{Discussion}

\section{Blood plasma modelling}

Table 1 shows the species distribution in blood plasma for each ligand. DMSA is the only ligand that has considerable binding to blood plasma metal ions. According to blood plasma modelling, DMBG (without Sn(II)), BIU and CBIG have virtually no interaction with blood plasma metal ions, while ITB experiences some complexation. As reported elsewhere [11], a significant (although not totally defined) change occurs in the species distribution of DMBG if Sn(II) is included. This implies that $\sim 25 \%$ of the ligand stays bound to $\mathrm{Sn}(\mathrm{II})$, as was already the case in the formulation preinjection, but will not mobilise other blood plasma metal ions. If one considers that the low stoichiometric amount of Tc in the formulation, $\mathrm{Sn}$ (II) will not significantly reduce the number of labelled DMBG sites, and neither will the other blood plasma ligands or metal ions, it may therefore be expected that the labelling of ${ }^{99 m}$ Tc DMBG will not be adversely influenced and that 
the biodistribution seen in animals will be that of the ligand. According to Table $2,6.9 \%$ of $\mathrm{Sn}$ (II) in the formulation is bound to DMBG, while the rest is distributed to other blood plasma ligands, which is in line with the normal biodistribution of $\mathrm{SnCl}_{2}$ [6]. For $\mathrm{BIU}$, the situation is identical and no mobilisation by blood plasma metal ions is predicted. Table 1 indicates that $10 \%$ of ITB is bound to $\mathrm{Mg}(\mathrm{II})$, while $1.5 \%$ of $\mathrm{CBIG}$ is bound by $\mathrm{Zn}(\mathrm{II})$. Together with the anticipated mobilisation of $\mathrm{Sn}(\mathrm{II})$ (in the order of $25 \%$ ), it is possible that the labelling might be influenced. This is reflected in Fig. 2, which shows that minor mobilisation of $\mathrm{Mg}(\mathrm{II})$ and $\mathrm{Zn}(\mathrm{II})$ is caused by ITB and CBIG, respectively. DMSA is the exception, as its speciation calculations show that almost $100 \%$ of the ligand is bound by $\mathrm{Zn}(\mathrm{II})$. As the complexation by $\mathrm{Zn}(\mathrm{II})$ is very strong, it is not expected that $\mathrm{Sn}(\mathrm{II})$ will alter the species distribution of DMSA in blood plasma. It is therefore expected that the biodistribution studied in animals with ${ }^{99 m}$ Tc-DMSA will be that of $\mathrm{Zn}(\mathrm{II})$-DMSA (more particularly $\left.\mathrm{Zn}_{2}(\mathrm{DMSA})_{2}(\mathrm{OH})_{2}\right)$ and not DMSA alone. This is reflected in Fig. $\underline{2}$, which shows that DMSA substantially mobilises $\mathrm{Zn}$ (II) metal ions, which might prompt one to give such patients $\mathrm{Zn}$ (II) supplements.

\section{Biodistribution and pharmacokinetics of ${ }^{99 \mathrm{~m}} \mathrm{TC}-\mathrm{L}$ and ${ }^{99 \mathrm{~m}} \mathrm{TC}-\mathrm{DMSA}$}

From Tables $\underline{3}$ and $\underline{4}$ it is clear that the biodistribution of DMSA is also altogether different from that of the other ligands. Most notable is the slow wash-out of all organs, including the blood plasma. Although from the blood plasma model it is predicted that the biodistribution in animals will be that of Zn(II)-DMSA and not DMSA alone, one should consider the small stoichiometric amount of Tc, which makes it conceivable that Tc will still be labelled to some of the DMSA molecules, assisted by a kinetically fast association and dissociation. Therefore, the reason for the slow washout can be explained by the association of DMSA with $\mathrm{Zn}(\mathrm{II})$, causing a biodistribution and retention in all organs all over the body, before the ligands ability to be excreted through the kidneys takes place. The biguanide-type ligands (DMBG for instance) also have a slow wash-out of some organs, most notably the gallbladder that serves as a target organ. It is postulated that the ligand is taken up by the liver and excreted through the gallbladder. In view of the fact that DMBG is a diabetic agent, uptake in liver or related organs was expected. ITB has a similar biodistribution to DMBG, although it clears faster from the blood plasma (Fig. $\underline{5}$ ). BIU almost instantaneously is taken up in the gallbladder while the blood clearance through the kidney is comparable with DMBG. CBIG has a fast wash-out of most organs, including the gallbladder, and its blood clearance is comparable to DMBG. All the compounds except DMSA have gallbladder uptake, as is seen in Tables $\underline{3}, \underline{4}$ and Fig. $\underline{4}$. The gallbladder uptake for the biguanide-type ligands overshadows their fast kidney uptake and clearance. This is expected, as all the molecules (except DMSA) are structurally similar. Of interest is the fast clearance through the liver into the gallbladder. This is in contrast with ${ }^{99 m}$ Tc-DMSA, which shows slower kidney clearance and the slowest urinary excretion (Fig. $\underline{6}$ ). The urinary excretion (Fig. $\underline{6}$ ) of ${ }^{99 \mathrm{~m}} \mathrm{Tc}-\mathrm{DMBG}$ and ${ }^{99 \mathrm{~m}} \mathrm{Tc}-\mathrm{BIU}$ is twice that of ${ }^{99 m}$ Tc-DMSA at 180 minutes, but the amount of gallbladder uptake (49 and $70 \%$, respectively) makes them unattractive as kidney agents (Fig. $\underline{5}$ ). ${ }^{99 m} \mathrm{Tc}$-ITB has a much higher urinary clearance after 180 minutes and a subsequent lower gallbladder uptake $(29 \%)$. It achieves the best kidney to gallbladder ratio (Table 4 ) of the biguanide derivatives viz. 0.4 after $30 \mathrm{~min}$ which is far less than 5.7 the kidney to liver ratio found for ${ }^{99 \mathrm{~m}} \mathrm{Tc}-\mathrm{DMSA}$ although this is only achieved after $3 \mathrm{~h} .{ }^{99 \mathrm{~m}} \mathrm{Tc}-\mathrm{CBIG}$ has a kidney to gallbladder ratio of 0.3 after $120 \mathrm{~min}$ and a fast clearance via the kidneys and very high urinary excretion, $92 \%$ at $180 \mathrm{~min}$. This results in very little uptake in all the other organs, including the kidneys, at $3 \mathrm{~h}$. This confirms the suspicion that the carboxyl group will influence the charge of the complex and therefore the totally different biodistribution recorded for ${ }^{99 \mathrm{~m}} \mathrm{Tc}$-CBIG if compared with ${ }^{99 \mathrm{~m}} \mathrm{Tc}-\mathrm{DMBG}$. The decline in $\%$ i.d. for the gallbladder for ${ }^{99 \mathrm{~m}} \mathrm{Tc}-\mathrm{CBIG}$ could be due to clearance into the intestine. The results clearly indicate that very low radiation doses can be expected in all organs for ${ }^{99 \mathrm{~m}} \mathrm{Tc}-\mathrm{CBIG}$, while it will only slightly mobilise $\mathrm{Zn}(\mathrm{II})$. Its fast clearance by the kidney into the urine gives it potential as a kidneyfunctioning agent. It will also improve on the slow kidney accumulation and high $\mathrm{Zn}(\mathrm{II})$ mobilisation of ${ }^{99 \mathrm{~m}} \mathrm{Tc}$-DMSA, which is only ready for scintigraphy after $3 \mathrm{~h}$. However, ${ }^{99 \mathrm{~m}} \mathrm{Tc}-\mathrm{CBIG}$ scintigraphy will be negatively influenced by its almost instant accumulation in the gallbladder and subsequent elimination from there. It is not foreseen that the latter will deliver a high dose to the gallbladder, as 
the excretion out of this organ is relatively fast $\left(\mathrm{t}_{1 / 2}=44 \mathrm{~min}\right.$, Table $\left.\underline{3}\right)$ but may interfere with analysis of images. The liver excretion of ${ }^{99 \mathrm{~m}} \mathrm{Tc}-\mathrm{DMSA}$ is much slower $\left(\mathrm{t}_{1 / 2}>180 \mathrm{~min}\right)$.

\section{Conclusion}

A number of biguanide derivatives were evaluated as potential kidney agents as compared to ${ }^{99 m}$ Tc-DMSA. It was shown that the agent ${ }^{99 \mathrm{~m}} \mathrm{Tc}-\mathrm{CBIG}$ has a very fast kidney clearance, which will reduce the dose to organs (as experienced for ${ }^{99 \mathrm{~m}}$ Tc-DMSA), although its potential as a kidney agent is limited by its gallbladder uptake. Blood plasma speciation studies (in the absence of Tc formation constants) proved useful in this case where strong Tc ligand binding was expected. If strong competition of blood plasma metal ions was predicted it could cause dissociation of the Tc complex in vivo. This was not the case and no dissociation was found in the in vivo experiments.

Acknowledgments The authors thank the South African Nuclear Energy Corporation for permission to publish this work, Dr. Neil Jarvis for initiating it and Dr. Werner Louw for the help with the radiolabelling.

\section{References}

1. Chervu, L.R., Blaufox, M.D.: Renal radiopharmaceuticals: an update. Sem. Nucl. Med. 12, 224-245 (1982)

2. Taylor, A. Jr., Eshima, D., Fritzberg, A.R., Christian, P.E., Kasina, S.: Preliminary evaluation of Tc-99m mercaptoacethyltriglycine (MAG3) as a replacement for I-131 OIH. J. Nucl. Med. 27, 571-572 (1986)

3. Neves, M., Gano, L.: Synthesis, characterization, and biodistribution of oxo complexes of Technetium-99m with biguanide and N1-substituted ligands. Nucl. Med. Biol 26, 79-83 (1999)

4. Neves, M., Dormehl, I.C., Kilian, E., Louw, W.K.A., Lalaoui, K., Pedrosu de Lima, J.J.P.: Evaluation in the baboon model of ${ }^{99 m}$ Tc-Biguanide as a tracer for renal imaging. Nucl. Med. Biol 27, 593-597 (2000)

5. Zeevaart, J.R., Jarvis, N.V., Louw, W.K.A., Jackson, G.E.: Metal-ion speciation in blood plasma incorporating the tetraphosphonate, N,N-dimethylenephosphonate-1-hydroxy-4-aminopropilydenediphosphonate (APDDMP), in therapeutic radiopharmaceuticals. J. Inorg. Biochem. 83, 57-65 (2001)

6. Zeevaart, J.R., Louw, W.K.A., Kolar, Z.I., Wagener, J.M., Jarvis, N.V., Claessens, R.A.M.J.: A thermodynamic approach (using speciation studies) towards the evaluation and design of bone-seeking radiopharmaceuticals as illustrated for ${ }^{117 m}$ Sn(II)-PEI-MP. J. Radioanal. Nucl. Chem. 257, 83-91 (2003)

7. Zeevaart, J.R., Jansen, D.R., Botelho, M.F., Abrunhosa, A., Gomes, C., Metello, L., et al.: Comparison of the predicted in vivo behaviour of the Sn(II)-APDDMP complex and the results as studied in a rodent model. J. Inorg. Biochem. 98, 1523-1530 (2004)

8. Matell, A.E., Smith, R.M. (eds.): NIST Standard Reference Database 46 Version 8.0. Gaithersburg, MD 20899 USA

9. Zeevaart, J.R., Olsen, S.C.: Recent trends in the concept of specific activity: impact on radiochemical and radiopharmaceutical producers. Appl. Rad. Isot. 64, 812-814 (2006)

10. DMSA Leaflet (L/4193/03), Amersham, Oct. 2001

11. Wagener, J.M., Dithebe, M.K., Mogano, M.D., Cukrowski, I., Zeevaart, J.R.: Modelling of the blood plasma species of biguanide derivates exhibiting potential as diagnostic radiopharmaceuticals. S.A. J. Chem. 61, 82-92 (2008) 
12. Marchi, A., Marvelli, L., Cattabriga, M., Rossi, R., Neves, M., Bertolasi, V., et al.: Technetium (V) and rhenium (V) complexes of biguanide derivatives. Crystal structures. Dalton Trans. 1937-1943 (1999)

13. Larsen, S.D., Connell, M.A., Cudahy, M.M., Evans, B.R., May, P.D., Meglasson, M.D., et al.: Synthesis and biological activity of analogues of the antidiabetic/antiobesity agent 3-guanidinopropionic acid: discovery of a novel aminoguanidinoacetic acid antidiabetic agent. J. Med. Chem. 44, 1217-1230 (2001)

14. Vaillancourt, V.A., Larsen, S.D., Tanis, S.P., Burr, J.E., Connell, M.A., Cudahy, M.M., et al.: Synthesis and biological activity of aminoguanidine and diaminoguanidine analogues of the antidiabetic/antiobesity agent 3guanidinopropionic acid. J. Med. Chem. 44, 1231-1248 (2001)

15. Eilingsfeld, H., Scheuermann, H.: Synthese von 1.3.5-Triazinen. Chem. Ber. 100, 1874-1891 (1967)

16. May, P.M., Williams, D.R., Linder, P.W.: Computer simulation of metal-ion equilibria in biofluids: models for the low-molecular-weight complex distribution of calcium(II), magnesium(II), manganese(II), iron(III), copper(II), zinc(II), and lead(II) ions in human blood plasma. Dalton Trans. 588-595 (1977) 